Introduction and objectives Randomised controlled trials of vitamin $\mathrm{D}$ to prevent acute respiratory infection have yielded mixed results. We conducted an individual patient data (IPD) meta-analysis to identify factors that may explain this heterogeneity.

Methods We performed an IPD meta-analysis of 25 trials of vitamin D supplementation with incidence of acute respiratory infection as a pre-specified outcome (total 11,321 participants, aged 0 to 95 years). We used one-step logistic regression with random effects adjusting for age, sex, study duration and clustering by study. Pre-specified sub-group analyses were done to determine whether effects of vitamin D on risk of acute respiratory infection varied according to baseline 25 -hydroxyvitamin $\mathrm{D}(25[\mathrm{OH}]$ D) concentration or dosing regimen.

Results IPD were obtained for 10,933/11,321 (96.6\%) participants. Vitamin D supplementation reduced risk of acute respiratory infection among all participants (adjusted Odds Ratio [aOR] $0.88,95 \% \mathrm{CI}: 0.81$ to $0.96, \mathrm{P}=0.003$; $\mathrm{P}$ for heterogeneity $<0.001)$. Sub-group analysis revealed a strong protective effect among individuals with baseline $25(\mathrm{OH}) \mathrm{D}<25 \mathrm{nmol} / \mathrm{L}$ (aOR $0.62,95 \% \mathrm{CI}: 0.45$ to $0.83, \mathrm{P}=0.002$ ), not seen among those with higher levels (aOR 0.91, 95\% CI: 0.78 to 1.05; Pinteraction $=0.01)$. A protective effect was also seen in individuals receiving daily or weekly vitamin $\mathrm{D}$ without additional bolus doses (aOR 0.81, 95\% CI: 0.72 to $0.91, \mathrm{P}<0.001$ ), but not in those receiving one or more bolus doses (aOR 0.97, 95\% CI: 0.86 to 1.10 , Pinteraction $=0.05$ ). Vitamin $\mathrm{D}$ did not influence the proportion of participants experiencing at least one serious adverse event (aOR 0.98, 95\% CI: 0.80 to $1.20, \mathrm{P}=0.83)$. The body of evidence contributing to these analyses was assessed as being of high quality.

Conclusions Vitamin D supplementation was safe, and it protected against acute respiratory infection overall. Very deficient individuals and those not receiving bolus doses experienced the most benefit.

\section{S103 NON-TYPEABLE HAEMOPHILUS INFLUENZAE DOWNREGULATES RELEASE OF BETA-DEFENSIN-1 FROM BRONCHIAL EPITHELIAL CELLS}

$\sqcup$ Tregidgo, JL Cane, M Bafadhel. Respiratory Medicine Unit, NDM, University of Oxford, Oxford, UK

\subsection{6/thoraxjnl-2016-209333.109}

Introduction Beta defensin-1 is an antimicrobial peptide released from epithelial cells, acting to defend the host against microbial activity and colonisation. It is possible that reduction in release of this antimicrobial peptide contributes to the host inability to remove bacteria from the airway. We investigated the release of beta-defensin-1 from the bronchial epithelium, with and without Non-Typeable Haemophilus influenzae (NTHi) infection and studied the effects of corticosteroids on this.

Method Human bronchial epithelial cells from three healthy donors were grown to $90 \%$ confluence. Cells were treated with $16 \mathrm{nM}, 1.6 \mathrm{nM}$ and $0.16 \mathrm{nM}$ Budesonide or $10 \mathrm{nM}, 1 \mathrm{nM}$ and $0.1 \mathrm{nM}$ Fluticasone propionate as per clinical equivalence, for two hours prior to addition of $1 \times 106$ CFU of NTHi. Cells were incubated for a further two hours. Beta-defensin-1 was measured in supernatants by ELISA.

Results NTHi infection downregulated beta-defensin-1 release by 42\% (mean basal release: $133.6 \mathrm{pg} / \mathrm{ml}, \mathrm{SD}: 61.6$, mean release with NTHi infection: $77.6 \mathrm{pg} / \mathrm{ml}, \mathrm{SD}: 50.6 . \mathrm{p}=0.0084)$. Addition of Budesonide or Fluticasone propionate to bronchial epithelial cells decreased beta-defensin-1 release from mean basal level to $106.2 \mathrm{pg} / \mathrm{ml}(\mathrm{SD}: 79.4, \mathrm{p}=0.023)$ and $100.6 \mathrm{pg} / \mathrm{ml}(\mathrm{SD}$ : $50.0, \mathrm{p}=0.083$ ) respectively. This release is synergistically decreased upon NTHi infection with Budesonide and Fluticasone propionate treatment (mean with NTHi: $67.3 \mathrm{pg} / \mathrm{ml}, \mathrm{SD}: 38.7$. $\mathrm{p}=0.039$ and $64.4 \mathrm{pg} / \mathrm{ml}, \mathrm{SD}: 26.1 . \mathrm{p}=0.048)$ respectively compared to corticosteroid treatment only. No difference in betadefensin-1 level was seen between low and high dose of either corticosteroid tested.

Conclusion NTHi inhibits beta-defensin-1 release from healthy bronchial epithelial cells. This release is dampened further by corticosteroid treatment and may be implicated in NTHi persistence in the airway in patients with chronic lung disease such as COPD.

\section{S104 HYPOXIA PRECONDITIONS THE INNATE IMMUNE RESPONSE TO ACUTE BACTERIAL PULMONARY INFECTIONS}

${ }^{1} \mathrm{RS}$ Dickinson, ${ }^{2} \mathrm{AAR}$ Thompson, ${ }^{1} \mathrm{JP}$ Thomson, ${ }^{1} \mathrm{~F}$ Murphy, ${ }^{2} \mathrm{HM}$ Marriott, ${ }^{1} \mathrm{~A}$ Tavares, ${ }^{1} \mathrm{~J}$ Willson, ${ }^{2} \mathrm{~L}$ Williams, ${ }^{2} \mathrm{~A}$ Lewis, ${ }^{1} \mathrm{~S}$ Forbes, ${ }^{1} \mathrm{RH}$ Stimson, ${ }^{2} \mathrm{AG}$ Hameed, ${ }^{2} \mathrm{JA}$ Preston, ${ }^{2} \mathrm{~A}$ Lawrie, ${ }^{2} \mathrm{~V}$ Finisguerra, ${ }^{3} \mathrm{M}$ Mazzone, ${ }^{2} \mathrm{SJ}$ Foster, ${ }^{4} \mathrm{ER}$ Chilvers, ${ }^{4} \mathrm{AS}$ Cowburn, ${ }^{2} \mathrm{DH}$ Dockrell, ${ }^{4} \mathrm{RS}$ Johnson, ${ }^{4} \mathrm{RR}$ Meehan, ${ }^{1} \mathrm{MKB}$ Whyte, ${ }^{1} \mathrm{SR}$ Walmsley. ${ }^{1}$ University of Edinburgh, Edinburgh, UK; ${ }^{2}$ University of Sheffield, Sheffield, UK; ${ }^{3}$ Vesalius Research Centre, Leuven, Belgium; ${ }^{4}$ University of Cambridge, Cambridge, UK

\subsection{6/thoraxjnl-2016-209333.110}

Introduction Systemic hypoxaemia and recurrent bacterial infections frequently co-exist in patients with acute and chronic lung disease and correlate with poor clinical outcomes. Inappropriate neutrophilic inflammation is regularly seen in these circumstances and the HIF/PHD pathway is implicated in the response of the innate immune system to both hypoxia and bacteria. Here we aimed to dissect and modify the interactions between hypoxia and innate host-pathogen response in the lung.

Methods C57BL/6 mice were either housed in room air or 'preconditioned' by being housed in $10 \%$ oxygen for 7 days. They then received intratracheal $1 \times 10^{7}$ type $2 \mathrm{~S}$. pneumoniae under recovery anaesthesia with subsequent exposure to hypoxia $(10 \%$ $\mathrm{O}_{2}$ ) or room air $\left(21 \% \mathrm{O}_{2}\right)$. Mice were assessed clinically, rectal temperatures recorded and culled for broncho-alveolar lavage (BAL) and tissue sampling (blood and lung) at various time points. Peripheral blood glucose was measured from tail vein venepuncture using a handheld blood glucose monitor. RNA from peripheral blood leucocytes was isolated and analysed using RNAseq. 18FDG-PET was performed on animals $14 \mathrm{~h}$ following infection to observe glucose utilisation. Histology was performed on formalin fixed sections for glycogen storage.

Results Exposure to acute hypoxia resulted in significant morbidity (sickness $(5.7$ vs $2.1, \mathrm{p}<0.02)$ and hypothermia $(31.8$ vs $\left.36.0^{\circ} \mathrm{C}, \mathrm{p}<0.05\right)$ ) and rapid $100 \%$ mortality by $48 \mathrm{~h}$ post infection. This response was independent of bacterial burden, and leukocyte recruitment. In keeping with a negative energy state, hypoxic mice displayed loss of liver glycogen, with increased serum ketone production and lower circulating glucose levels. Preconditioned mice showed marked protection from both the acute hypoxia-associated systemic phenotype and the negative energy state. Transfer of preconditioned bone marrow to naïve mice also rescued the pathophysiological response. RNAseq analysis of the circulating leukocyte population identified signalinduced suppression of HIF-1a pathway genes, which were linked to reduced leukocyte glucose utilisation in vivo by $18 \mathrm{FDG}$-PET. 